\title{
Letter \\ The quest for optimal positive end-expiratory pressure continues
} Dick Markhorst, Martin Kneyber and Marc van Heerde

Pediatric Intensive Care Unit, VU University Medical Center, PO Box 7057, 1007 MB Amsterdam, The Netherlands

Corresponding author: Dick Markhorst, dg.markhorst@vumc.nl

Published: 21 February 2008

Critical Care 2008, 12:408 (doi:10.1186/cc6208)

This article is online at http://ccforum.com/content/12/1/408

(C) 2008 BioMed Central Ltd

See related research by Carvalho et al., http://ccforum.com/content/11/4/R86

and see related commentary by Rouby et al., http://ccforum.com/content/11/6/180

With interest we have read the paper by Carvalho and colleagues, in which the authors report the results of their elegant study on the role of positive end-expiratory pressure (PEEP) in acute lung injury [1]. Carvalho and colleagues demonstrated in an acute respiratory distress syndrome (ARDS) model that alveolar hyperinflation and nonaerated areas may coincide during a stepwise reduction of PEEP. Their finding is in line with our findings in a mathematical ARDS model and with other studies [2,3], and emphasises that the PEEP at which the respiratory system compliance is maximal coincides with a compromise between hyperinflation and poor aeration [3].

The accompanying commentary by Rouby and colleagues, however, raises questions about the contribution by Carvalho and colleagues on which we would like to comment [4]. First, Rouby and colleagues state that PEEP may produce endexpiratory hyperinflation of aerated areas. This statement is clear, but the authors also state that PEEP produces endexpiratory reaeration of nonaerated parts of the lung (recruitment). This last statement is puzzling, since PEEP is an end- expiratory phenomenon and as such cannot in itself recruit collapsed lung units. PEEP can maintain volume that has been recruited by higher pressures.

Second, we fully agree that a lung-protective ventilator strategy should not only include a reduced tidal volume, but also should combine a PEEP level that corresponds to an optimal compromise between alveolar recruitment and hyperinflation. Rouby and colleagues conclude that this compromise yields equal numbers of hyperinflated and nonaerated lung regions. Evidently, both regional consolidation and regional hyperinflation may lead to ventilator-induced lung injury [5]. To our knowledge, however, whether both are equally harmful has yet to be demonstrated Furthermore (at least during high-frequency oscillatory ventilation), airway pressures at which oxygenation is maximal do not equal pressures at which the respiratory system compliance is maximal [6]. We therefore propose that for the survival of the individual patient it is unclear whether to aim at optimal oxygenation or at optimal compliance.

\section{Authors' response}

Jean-Jacques Rouby, Fabio Ferrari, Bélaïd Bouhemad and Qin Lu

We thank Dr Markhorst and colleagues for their comment. We fully agree that PEEP prevents end-expiratory derecruitment and does not provide lung recruitment per se. When referring to the effects of PEEP, it is true that it would have been more appropriate to replace recruitment with prevention of derecruitment as we did in a recent paper measuring the effect of PEEP on lung aeration [7].

The second comment raises important questions. There is clear evidence that regional lung inflammation is not only caused by cyclic opening and closing of distal lung units, but also by hyperinflation of aerated lung units: this has been shown in patients with ARDS [8] and in patients with healthy lungs undergoing mechanical ventilation during general anaesthesia [9]. As shown in Figure 1, in ARDS survivors the distribution of pseudo cysts and bronchiectasis characterizing late ventilator-induced lung injury [10] is exactly the same as the distribution of lung hyperinflation measured in the early phase [11]. Such a result clearly suggests that initial pulmonary hyperinflation is the prelude to secondary lung distortion and bronchial damage, and that early ventilator-induced hyperinflation has a significant secondary harmful impact. 
(a)

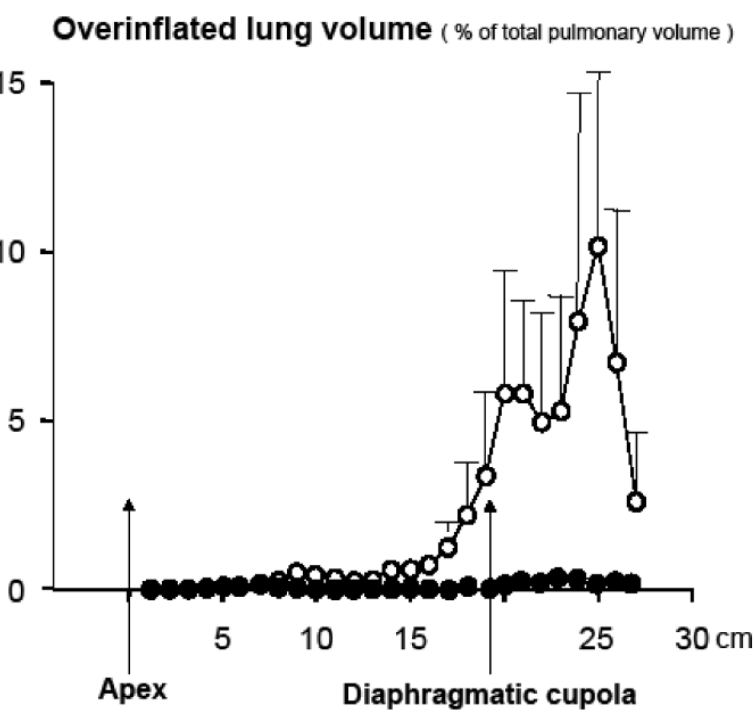

(b)

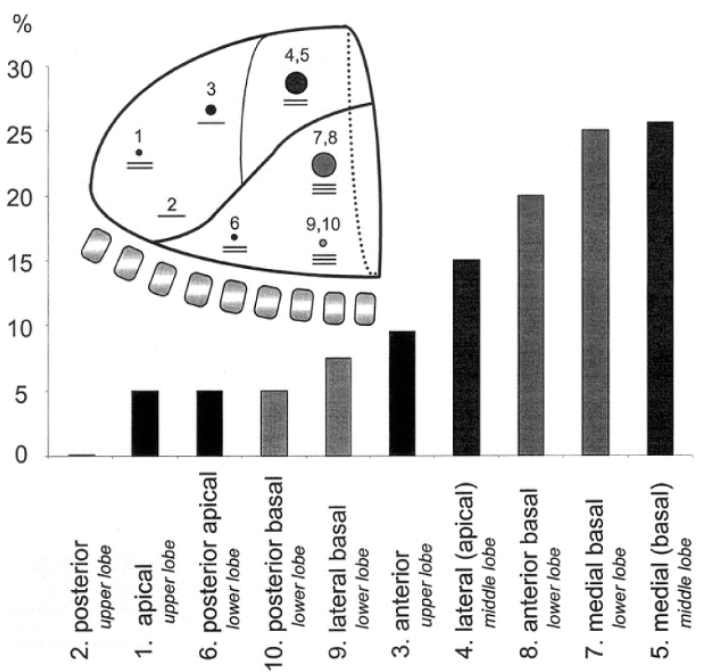

(a) Cephalocaudal distribution of computed tomography (CT) end-expiratory hyperinflated lung volume (expressed as a percentage of the total pulmonary volume) in eight patients studied during the first 6 days of acute lung injury at positive end-expiratory pressures of $15 \mathrm{cmH}_{2} \mathrm{O}$ (open circles) and $0 \mathrm{cmH}_{2} \mathrm{O}$ (closed circles). Reproduced with permisson of Lippincott Williams and Wilkins from [5]. (b) Segmental distribution of the CT cumulated amount of air cysts (filled circles) and bronchiectasis (horizontal lines), expressed as a percentage of each lung segment (numbers), in 21 patients with acute respiratory distress syndrome studied 3 weeks after the onset of their respiratory disease. Reproduced with permisson of Lippincott Williams and Wilkins from [4]. The distribution of early CT hyperinflation coincides with the distribution of late air cysts and late bronchiectasis.

It is true that the best oxygenation does not coincide with the best compliance. The relevant issue remains, however, whether high oxygenation levels are of any significant benefit compared with oxygenation levels providing arterial oxygen saturation $>90 \%$ and oxygen transportation sufficient to meet tissue oxygen demand. A strategy aimed at obtaining the highest arterial oxygenation cannot be considered safe if the price to pay is early hyperinflation with impaired cardiac output and oxygen transportation followed by late bronchial and alveolar damage.

\section{Competing interests}

The authors declare that they have no competing interests.

\section{References}

1. Carvalho ARS, Jandre FC, Pino AV, Bozza FA, Salluh J, Rodrigues R, Ascoli FO, Giannella-Neto A: Positive end-expiratory pressure at minimal respiratory elastance represents the best compromise between mechanical stress and lung aeration in oleic acid induced lung injury. Crit Care 2007, 11:R86.

2. Markhorst DG, Van Genderingen HR, Van Vught AJ: Static pressure-volume curve characteristics are moderate estimators of optimal airway pressures in a mathematical model of (primary/pulmonary) acute respiratory distress syndrome. Intensive Care Med 2004, 30:2086-2093.

3. Ward NS, Lin DY, Nelson DL, Houtchens J, Schwartz WA, Klinger $\mathrm{JR}$, et al.: Successful determination of lower inflection point and maximal compliance in a population of patients with acute respiratory distress syndrome. Crit Care Med 2002, 30:963-968.
4. Rouby JJ, Ferrari F, Bouhemad B, Lu Q: Positive end-expiratory pressure in acute respiratory distress syndrome: should the 'open lung strategy' be replaced by a 'protective lung strategy'? Crit Care 2007, 11:180.

5. Marini JJ, Gattinoni L: Ventilatory management of acute respiratory distress syndrome: a consensus of two. Crit Care Med 2004, 32:250-255.

6. Markhorst DG, Jansen JR, Van Vught AJ, Van Genderingen HR: Breath-to-breath analysis of abdominal and rib cage motion in surfactant-depleted piglets during high-frequency oscillatory ventilation. Intensive Care Med 2005, 31:424-430.

7. Lu Q, Constantin JM, Nieszkowska A, Elman M, Vieira S, Rouby JJ: Measurement of alveolar derecruitment in patients with acute lung injury: computed tomography versus pressure-volume curve. Crit Care 2006, 10:R95

8. Terragni PP, Rosboch G, Tealdi A, Corno E, Menaldo E, Davini O, Gandini G, Herrmann P, Mascia L, Quintel M, Slutsky AS, Gattinoni L, Ranieri VM: Tidal hyperinflation during low tidal volume ventilation in acute respiratory distress syndrome. Am J Respir Crit Care Med 2007, 175:160-166.

9. Schultz MJ, Haitsma JJ, Slutsky AS, Gajic O: What tidal volumes should be used in patients with acute lung injury? Anesthesiology 2007, 106:1085-1087.

10. Treggiari MM, Romand JA, Martin JB, Suter PM: Air cysts and bronchiectasis prevail in nondependent areas in severe acute respiratory distress syndrome: a computed tomographic study of ventilator-associated changes. Crit Care Med 2002, 30:1747-1752.

11. Nieszkowska A, Lu Q, Vieira S, Elman M, Fetita C, Rouby JJ: Incidence and regional distribution of lung overinflation during mechanical ventilation with positive end-expiratory pressure. Crit Care Med 2004, 32:1496-1503. 